Pak. J. Agri. Sci., Vol. 58(4),1315-1321;2021

ISSN (Print) 0552-9034, ISSN (Online) 2076-0906

DOI: 10.21162/PAKJAS/21.675

http://www.pakjas.com.pk

\title{
Mineral profiling of resistant and susceptible tomato varieties against Alternaria solani causing early blight
}

\author{
Shafqat Ali ${ }^{1}$, Muhammad Atiq ${ }^{1, *}$, Shahbaz Talib Sahi ${ }^{1}$ and Muhammad Arshad ${ }^{2}$ \\ ${ }^{1}$ Department of Plant Pathology, University of Agriculture, Faisalabad, Pakistan; ${ }^{2}$ Department of Entomology, University of \\ Agriculture, Faisalabad, Pakistan \\ *Corresponding author's e-mail: dratiqpp@gmail.com
}

\begin{abstract}
The current research was conducted to investigate the alterations in the mineral status in the leaves of tomato plants against early blight (EB) caused by Alternaria solani. Six tomato varieties; viz. Riograndae, Roma and Basket (resistant) and T-88572, BHN-961 and BHN-1021(susceptible) were inoculated with a blend of five isolates of Alternaria solani, collected from different regions of Faisalabad District. These six varieties for mineral profiling were selected after two years screening from twenty-five varieties of tomatoes under field conditions. These varieties were sown in pots and artificial inoculation was performed to develop disease in inoculated type of tomato plants while distilled water was applied on un-inoculated type of plants. Newly infected leaves from upper, middle and lower parts of tomato plants from resistant and susceptible groups were used to prepare sample for mineral analysis at $p \leq 0.05$ and variation in mineral profiling of resistant and susceptible groups of tomato plants was determined through Nested Structured Design. Significant variation was observed in inoculated (3.12, 0.48 $\%, 1.17,0.14,0.42,0.21,0.69$ and $1.49 \mathrm{ppm}$ and un-inoculated type $(8.67,1.61 \%, 10.45,0.22,1.75,1.98,3.09$ and $3.39 \mathrm{ppm})$ while resistant group expressed $6.59,1.19 \%, 8.13,1.973,1.69,1.26,1.36,2.43$ and $2.87 \mathrm{ppm}$ and susceptible group exhibited $5.19,0.91 \%, 5.69,1.693,1.24,0.91,0.83,1.35$ and $2.22 \mathrm{ppm}$ with respect to NPK, Ca, Mg, Na, Zn, Iron and copper. Resistant variety, Riograndae expressed maximum amount while T-88572 exhibited minimum amount of all mineral contents. Alterations in the mineral profiling in leaves of tomato plants can be used by researchers as biochemical markers for identification and development of resistant source against early blight of tomato and for the development of ecofriendly management strategy towards A. solani.
\end{abstract}

Keywords: Alternaria solani, lycopersicon esculentum, metabolic reactions, carotenes, lycopene.

\section{INTRODUCTION}

Tomato (Lycopersicon esculentum Mill) is the most imperative vegetable crop that is grown around the world (Mari and Lohano 2007) and belongs to family Solanaceae (Khan et al., 2014). It contains vitamins A, C, and E (Naik et al., 2010) and nutrients (27 $\mathrm{mg}$ phosphorus, $13 \mathrm{mg}$ calcium, $0.5 \mathrm{mg}$ iron, $3 \mathrm{mg}$ sodium and $244 \mathrm{mg}$ potassium) $/ 100 \mathrm{~g}$ of tomato (Sgherri et al., 2008). It contains anti-carcinogenic agents (carotenes and lycopene), thiamine, riboflavin, niacin and ascorbic acid Olaniyi et al., 2010). Worldwide, 4848 thousand hectares are cultivated with 182.3 million tons of tomato produce annually. In Pakistan, tomatoes are cultivated on 63.2 thousand hectares with 0.601 million tons production annually (FAOSTAT, 2017). Alternaria solani causes early blight (EB), or target spot disease of tomato (Momel and Pemezny 2006), which appears as small spots in yellow to dark-brown color in concentric rings on the leaves (Gleason and Edmunds 2006). These rings later on spread to entire foliage and stems, causing defoliation and death of plants (Chaerani et al., 2007), with 20 to $80 \%$ incidence of disease as observed by Akhtar et al., (2011) and Grigolli et al., (2011). Plant nutrients play a prime role in the defense system of plants, are classified into four groups based on biochemical and physiological behavior (Mitra 2015). The main elements of organic substances are $\mathrm{C}, \mathrm{H}, \mathrm{O}, \mathrm{N}$ and $\mathrm{S}$ that are involved in oxidation-reduction and enzymatic reactions. The second group $(\mathrm{P}$ and $\mathrm{B})$ regulates the energy transfer reactions. Elements of third group $(\mathrm{K}, \mathrm{Ca}, \mathrm{Cl}, \mathrm{Mn}$ and $\mathrm{Mg}$ ) works as catalysts, involved in osmotic and ion balance processes while fourth group minerals $(\mathrm{Cu}, \mathrm{Fe}, \mathrm{Zn}$ and $\mathrm{Mo})$ are known as structural chelates (Mengel 2001; Mengel et al., 2001). In addition, to $\mathrm{C}, \mathrm{H}$ and $\mathrm{O}$, plants require many essential nutrients. Nitrogen is an essential component of all organic compounds, phosphorus regulates metabolism and potassium works as an activator of several enzymes through ionic regulation (Malvi 2011). Ca is involved in cell division and maintains the integrity of membranes. $\mathrm{Mg}$ works as co-factor

Ali, S., M. Atiq, S. T. Sahi and M. Arshad.. 2021. Mineral profiling of resistant and susceptible tomato varieties against Alternaria solani causing early blight . Pak. J. Agri. Sci. 58:1315-1321.

[Received 10 Jun 2020; Accepted 26 May 2021; Published (online) 21 Sep 2021]

(c) (1)

Attribution 4.0 International (CC BY 4.0) 
in chlorophyll's enzymatic reactions, Sulfur maintains cell energetic process and iron is involved in key metabolic functions (Fageria and Stone 2006). Zinc is a core element of several proteinases, dehydrogenases and peptidases. Copper is a constituent of several important enzymes, including ascorbic acid oxidase, cytochrome oxidase and laccase. All of these play an important part in the defense mechanism of the plant (Datnoff et al., 2007).

An increase or decrease in quantity of ionic contents of a plant, play an imperative role in the plant growth and disease severity as well as virulence of a pathogen. When the pathogen attacks, it competes with host plant for $\mathrm{Na}, \mathrm{Ca}, \mathrm{Mg}$, $\mathrm{K}, \mathrm{NO}_{3}, \mathrm{SO}_{4}, \mathrm{H}_{2} \mathrm{PO}_{4}$ and $\mathrm{Cl}$ to cause infection by deionizing them or by increasing or decreasing their concentration in the plant (Capula-Rodríguez et al., 2016). This change affects the plant's health and vigor. The transportation and utilization of nutrients in the plant and soil are also restricted by the pathogen. Causal agent of early blight is very destructive as it reduces the plant's uptake efficiency of minerals and the imbalance of plant nutrients causes physiological and metabolic problems, toxicities and enhances susceptibility in tomato plants towards pathogens (Huber and Jones 2013). Aim of the current study was to assess the mineral contents of healthy and diseased tomato leaves to determine the mineral concentration of $\mathrm{N}, \mathrm{P}, \mathrm{K}, \mathrm{Ca}, \mathrm{Mg}, \mathrm{Na}, \mathrm{Cu}, \mathrm{Fe}$ and $\mathrm{Zn}$ to sustain the health of plant when caused by A. solani. These alterations in mineral contents can be used by researchers and scientist as biochemical markers for identification of resistant source in the available germplasm of tomato. These sources are helpful to developing eco-friendly management strategy towards early blight of tomato.

\section{MATERIALS AND METHODS}

Establishment and inoculation of tomato plants under greenhouse conditions: After two years' screening of twentyfive tomato varieties under CRD, six varieties were selected for mineral profiling. Three (Riograndae, Basket and Roma) out of six were resistant and three (T-88572, BHN-1021 and BHN-961) expressed susceptible response to A. solani. A nursery of these varieties was established in the experimental area of Plant Pathology Department, University of Agriculture Faisalabad (UAF). The plants were transferred in the pots $(32 \times 22 \mathrm{~cm})$ after 30 days that were filled with sterilized loamy soil (with formalin, 320:1) and kept on the bench in green house under 3 replications. After 25 days, young leaves of tomato plants were inoculated in the morning (when maximum stomata were opened) with $1 \times 10^{8}$ spores $/ \mathrm{mL}$ of fungal suspension (mixture of five isolates of $A$. solani) by using hand sprayer. Fungal spore concentration was determined by using hemocytometer (Horshman PA. 19044). Symptoms of early blight appeared on leaves after seven days of inoculation and gradually spread to entire foliage. Newly infected 15 leaves from upper, middle and lower portion of tomato plants were collected from inoculated and un-inoculated plants from both resistant and susceptible groups for the determination of ionic contents (Gomez and Gomez, 1984).

Determination of ionic status of leaves from inoculated and un-inoculated tomato plants: Plant samples were oven-dried in paper bags (Heraeus D 6450) for $48 \mathrm{~h}$ at $70^{\circ} \mathrm{C}$, ground with sterilized mortar and pestle. A $100 \mathrm{mg}$ quantity from dried, ground samples, was boiled in $10 \mathrm{~mL}$ of $1.4 \mathrm{~N}^{\circ} \mathrm{HNO}_{3}$ on a hotplate (TH550, Adv. Tokyo) at $100{ }^{\circ} \mathrm{C}$ for $30 \mathrm{~min}$. The suspension was cooled at room temperature and diluted in 250 $\mathrm{mL}$ distilled water. Then samples were analyzed through spectrophotometer (BEL: Model L.24) and flame photometer for determination of $\mathrm{N}, \mathrm{P}, \mathrm{K}, \mathrm{Ca}, \mathrm{Mg}, \mathrm{Na}, \mathrm{Cu}, \mathrm{Fe}$ and $\mathrm{Zn}$ (Bhargava and Raghupathi 1993; Bhargava and Raghupathi 1995).

For determination of Phosphorus, an aliquot of the solution $(0.1 \mathrm{~mL})$ was placed in a $100 \mathrm{~mL}$ volumetric flask then $8.6 \mathrm{~mL}$ distilled water and $1 \mathrm{~mL}$ of Ammonium Molybdate were added in it. The flask was swirled to mix the solution after adding Amino-naphthol Sulphonic Acid $(0.4 \mathrm{~mL})$. Absorbance of this solution was measured at $720 \mathrm{~nm}$ on a spectrophotometer (BEL: Model L.24) by using distilled water as blank. Phosphorus quantity was determined by comparing the absorbency to a previously prepared standard curve (Boltz and Mellon 1948). K and Na were measured by using flame photometer (PFP7/C). For the quantification of potassium $(\mathrm{K})$ and sodium $(\mathrm{Na})$, Potassium Chloride $(\mathrm{KCl})$ and Sodium Chloride $(\mathrm{NaCl})$ were used as standards. Standard curves for $\mathrm{K}$ and $\mathrm{Na}$ were prepared by using same concentrations $(10,20,30$ and $40 \mathrm{ppm})$ for both the elements. Fresh working standards were prepared immediately before use (Helrich 1990) while $\mathrm{Mg}, \mathrm{Ca}, \mathrm{Fe}, \mathrm{Cu}$ and $\mathrm{Zn}$ were determined by using spectrophotometer (BEL: Model L.24). For the determination of these ions, Calcium Chloride $\left(\mathrm{CaCl}_{2}\right)$, Magnesium Sulphate $\left(\mathrm{MgSO}_{4}\right)$, Iron Sulphate $\left(\mathrm{FeSO}_{4}\right)$, Copper Sulphate $\left(\mathrm{CuSO}_{4}\right)$ and Zinc oxide $(\mathrm{ZnO})$ were used as standards respectively.

Total nitrogen contents in each sample were determined by using Micro Kjeldahl Apparatus A dried sample of $100 \mathrm{mg}$ was placed in a long neck of $250 \mathrm{~mL}$ flask and $25 \mathrm{~mL}$ conc. $\mathrm{H}_{2} \mathrm{SO}_{4}$ and $5 \mathrm{~mL} \mathrm{CuSO}_{4}$ was added in it. The flask was heated in a sand bath until the solution was clear. Solution was then transferred into dissolution flask and treated with $10 \mathrm{~mL}$ of $40 \% \mathrm{NaOH}$. The liberated ammonia was distilled, and absorbance was determined for the volume of standard acid solution. Amount of unused acid was determined by back titration with standard $\mathrm{NaOH}$ solution (Jung et al., 2003). The percentage of nitrogen was calculated by using the formula:

$$
\text { Nitrogen } \%=\frac{\text { Volume of } 0.1 \mathrm{~N} \mathrm{H}_{2} \mathrm{SO}_{4} \times 0.0014 \times 250}{\text { Weight of sample } \times \text { Vol. of sample }} \times 100
$$

Statistical Analysis: Tomato plant population entailed of two groups (inoculate and un-inoculated) and each group of tomato plants contained two types; resistant and susceptible. Susceptible type contained three varieties/ advanced lines of tomato namely T-88572, BHN-1021 and BHN-961 while resistant type contained Riograndae, Basket and Roma. For estimation of mineral contents, standard analytical methods 
via Nested Structured Design (Gomez and Gomez 1984) were used and data were statistically analyzed by Statistical Analysis System (Institute 2009).

\section{RESULTS}

The resistant plants had significantly higher concentrations $(p<0.05)$ of all of the elements than the susceptible ones, for both the un-inoculated and inoculated plants. Significant difference of nitrogen was observed between inoculated $(3.12 \%)$ and un-inoculated $(8.67 \%)$ group (Table 2$)$.

Table 1. Nested ANOVA of mineral concentrations (N, P, K, Na, Ca, Mg, Zn, Fe and Cu) of inoculated and un-inoculated tomato plant leaves.

\begin{tabular}{|c|c|c|c|c|c|c|c|}
\hline SOV & DF & $\mathbf{S S}$ & MS & F value & Pr>F & Variance component & $\%$ of total \\
\hline \multicolumn{8}{|c|}{ Nitrogen (\%) } \\
\hline Type (A) & 1 & 834.444 & 834.444 & $0.033 *$ & 28.796 & 14.916 & 92.84 \\
\hline Group (B) & 2 & 57.956 & 28.978 & $0.000 *$ & 28.433 & 1.036 & 6.45 \\
\hline Variety (C) & 8 & 8.153 & 1.019 & $0.000 *$ & 899.444 & 0.113 & 0.70 \\
\hline Error & 96 & 0.108 & 0.001 & & & 0.001 & 0.01 \\
\hline Total & 107 & 900.663 & & & & 16.066 & \\
\hline \multicolumn{8}{|c|}{ Phosphorus (\%) } \\
\hline Type (A) & 1 & 34.612 & 34.612 & $0.030 *$ & 32.247 & 0.621 & 93.01 \\
\hline Group (B) & 2 & 2.146 & 1.073 & $0.003 *$ & 12.774 & 0.037 & 5.49 \\
\hline Variety (C) & 8 & 0.672 & 0.084 & $0.000 *$ & 111.551 & 0.009 & 1.39 \\
\hline Error & 96 & 0.072 & 0.007 & & & 0.001 & 0.11 \\
\hline Total & 107 & 37.503 & & & & 0.668 & \\
\hline \multicolumn{8}{|c|}{ Potassium (ppm) } \\
\hline Type (A) & 1 & 1351.007 & 1351.007 & $0.050 *$ & 16.831 & 23.532 & 88.61 \\
\hline Group (B) & 2 & 160.539 & 80.269 & $0.000 *$ & 113.824 & 2.947 & 11.10 \\
\hline Variety (C) & 8 & 5.641 & 0.705 & $0.000 *$ & 598.997 & 0.078 & 0.29 \\
\hline Error & 96 & 0.113 & 0.001 & & & 0.001 & 0.00 \\
\hline Total & 107 & 1517.308 & & & & 26.558 & \\
\hline \multicolumn{8}{|c|}{ Calcium (ppm) } \\
\hline Type (A) & 1 & 48.066 & 48.066 & $0.021 *$ & 45.204 & 0.870 & 92.83 \\
\hline Group (B) & 2 & 2.126 & 1.063 & $0.025 *$ & 6.043 & 0.033 & 3.51 \\
\hline Variety (C) & 8 & 1.407 & 0.176 & $0.000 *$ & 10.594 & 0.018 & 1.89 \\
\hline Error & 96 & 1.594 & 0.016 & & & 0.017 & 1.77 \\
\hline Total & 107 & 53.195 & & & & 0.938 & \\
\hline \multicolumn{8}{|c|}{ Magnesium (ppm) } \\
\hline Type (A) & 1 & 110.697 & 110.697 & $0.033 *$ & 28.623 & 1.978 & 92.74 \\
\hline Group (B) & 2 & 7.735 & 3.867 & $0.000 *$ & 25.766 & 0.138 & 6.45 \\
\hline Variety (C) & 8 & 1.200 & 0.150 & $0.000 *$ & 234.340 & 0.017 & 0.78 \\
\hline Error & 96 & 0.062 & 0.001 & & & 0.001 & 0.03 \\
\hline Total & 107 & 119.693 & & & & 2.133 & \\
\hline \multicolumn{8}{|c|}{ Sodium (ppm) } \\
\hline Type (A) & 1 & 47.893 & 47.893 & $0.033 *$ & 28.611 & 0.856 & 92.29 \\
\hline Group (B) & 2 & 3.347 & 1.673 & $0.002 *$ & 13.924 & 0.058 & 6.21 \\
\hline Variety (C) & 8 & 0.961 & 0.120 & $0.000 *$ & 187.282 & 0.013 & 1.43 \\
\hline Error & 96 & 0.061 & 0.005 & & & 0.001 & 0.07 \\
\hline Total & 107 & 52.264 & & & & 0.927 & \\
\hline \multicolumn{8}{|l|}{ Zinc (ppm) } \\
\hline Type (A) & 1 & 84.384 & 84.384 & $0.050 *$ & 14.277 & 1.453 & 86.06 \\
\hline Group (B) & 2 & 11.821 & 5.910 & $0.000 *$ & 27.235 & 0.211 & 12.49 \\
\hline Variety (C) & 8 & 1.736 & 0.217 & $0.000 *$ & 478.084 & 0.024 & 1.43 \\
\hline Error & 96 & 0.043 & 0.004 & & & 0.000 & 0.03 \\
\hline Total & 107 & 97.985 & & & & 1.689 & \\
\hline \multicolumn{8}{|l|}{ Iron (ppm) } \\
\hline Type (A) & 1 & 155.998 & 155.998 & $0.01 *$ & 7.233 & 2.489 & 70.46 \\
\hline Group (B) & 2 & 43.137 & 21.568 & $0.000 *$ & 40.611 & 0.779 & 22.05 \\
\hline Variety (C) & 8 & 4.248 & 0.531 & $0.027 *$ & 2.297 & 0.033 & 0.94 \\
\hline Error & 96 & 22.199 & 0.231 & & & 0.231 & 6.55 \\
\hline Total & 107 & 225.584 & & & & 3.533 & \\
\hline \multicolumn{8}{|c|}{ Copper (ppm) } \\
\hline Type (A) & 1 & 97.261 & 97.261 & $0.021 *$ & 6.826 & 1.537 & 73.93 \\
\hline Group (B) & 2 & 28.498 & 14.249 & $0.000 *$ & 78.623 & 0.521 & 25.06 \\
\hline Variety (C) & 8 & 1.449 & 0.181 & $0.000 *$ & 191.523 & 0.020 & 0.96 \\
\hline Error & 96 & 0.090 & 0.008 & & & 0.001 & 0.05 \\
\hline Total & 107 & 127.300 & & & & 2.079 & \\
\hline
\end{tabular}

*= Significant, $\mathrm{ns}=$ non-significant 
Table 2. Amounts of $\mathrm{N}, \mathrm{P}, \mathrm{K}, \mathrm{Ca}, \mathrm{Mg}$, $\mathrm{Na}, \mathrm{Zn}, \mathrm{Fe}$ and $\mathrm{Cu}$ in reaction groups (inoculated and un-inoculated), types (resistant and susceptible) varieties/lines of tomato plants.

\begin{tabular}{|c|c|c|c|c|c|c|c|c|c|c|c|c|}
\hline \multirow{4}{*}{$\begin{array}{l}\text { Varieties (C) } \\
\text { Types (B) } \\
\text { Groups (A) }\end{array}$} & \multicolumn{8}{|c|}{ Nitrogen $(\%)$} & \multirow{2}{*}{\multicolumn{2}{|c|}{ BHN-1021 }} & \multirow{2}{*}{\multicolumn{2}{|c|}{ BHN-961 }} \\
\hline & \multicolumn{2}{|c|}{ Riograndae } & \multicolumn{2}{|c|}{ Basket } & \multicolumn{2}{|c|}{ Roma } & \multicolumn{2}{|c|}{ T-88572 } & & & & \\
\hline & \multicolumn{6}{|c|}{ Resistant } & & & \multicolumn{2}{|c|}{ Susceptible } & & \\
\hline & Inoc. & Unino & Inoc. & Unino & Inoc. & Unino & Inoc & Unino & Inoc & Unino & Inoc & Unino \\
\hline Value of $\mathrm{N}$ in $(\mathrm{C})$ & 3.92 & 9.91 & 3.18 & 9.15 & 3.76 & 9.64 & 2.25 & 7.76 & 2.59 & 7.95 & 2.97 & 7.59 \\
\hline Av. val. of $\mathrm{N}$ in $(\mathrm{C})$ & \multicolumn{2}{|c|}{6.92} & \multicolumn{2}{|c|}{6.17} & \multicolumn{2}{|c|}{6.70} & \multicolumn{2}{|c|}{5.01} & \multicolumn{2}{|c|}{5.27} & \multicolumn{2}{|c|}{5.29} \\
\hline Av. val. of $N$ in (B) & \\
\hline Av. val. of $N$ in $(A)$ & \multicolumn{12}{|c|}{ Un-Inoculated $=8.67$ Inoculated $=3.12$} \\
\hline \multicolumn{13}{|c|}{ Phosphorus (\%) } \\
\hline Value of $\mathrm{P}$ in $(\mathrm{C})$ & 0.62 & 1.77 & 0.56 & 1.64 & 0.64 & 1.87 & 0.25 & 1.35 & 0.35 & 1.47 & 0.46 & 1.56 \\
\hline Av. val. of Pin (C) & & & & & & & & & & & & \\
\hline Av. val. of $P$ in (B) & & & & & Resista & $=1.19$ & iscepti & $\mathrm{e}=0.91$ & & & & \\
\hline Av. val. of $\mathrm{P}$ in $(\mathrm{A})$ & & & & & n-Inocu & ted $=1$ & Inocu & ted $=0$. & & & & \\
\hline & & & & Pot & ssium ( & om) & & & & & & \\
\hline Value of $\mathrm{K}$ in $(\mathrm{C})$ & 4.88 & 11.92 & 4.14 & 11.52 & 4.56 & 11.77 & 2.04 & 8.87 & 2.47 & 9.44 & 2.16 & 9.20 \\
\hline Av. val. of $\mathrm{K}$ in $(\mathrm{C})$ & & & & & & & & & & & & \\
\hline Av. val. of $\mathrm{K}$ in (B) & & & & & Resista & $=8.13$ & Iscepti & $e=5.69$ & & & & \\
\hline Av. val. of $K$ in (A) & & & & & -Inocul & $\mathrm{ed}=10$. & 5 Inoct & ated $=3$ & & & & \\
\hline & & & & & $\operatorname{cium}(\mathrm{p}$ & & & & & & & \\
\hline Value of $\mathrm{Ca}$ in $(\mathrm{C})$ & 1.39 & 2.74 & 1.20 & 2.52 & 1.30 & 2.69 & 0.86 & 2.25 & 0.98 & 2.35 & 1.27 & 2.45 \\
\hline Av. val. of $\mathrm{Ca}$ in $(\mathrm{C})$ & & & & & & & & & & & & \\
\hline Av. val. of $\mathrm{Ca}$ in (B) & & & & & esistan & $=1.973$ & Iscepti & $e=1.69$ & & & & \\
\hline Av. val. of $\mathrm{Ca}$ in (A) & & & & & n-Inocu & ted $=2.5$ & Inocu & ted $=1$. & & & & \\
\hline & & & & Ma: & hesium & $\mathrm{pm})$ & & & & & & \\
\hline Value of $\mathrm{Mg}$ in $(\mathrm{C})$ & 0.54 & 2.86 & 0.45 & 2.73 & 0.64 & 2.96 & 0.25 & 1.93 & 0.36 & 2.14 & 0.50 & 2.27 \\
\hline Av. val. of $\mathrm{Mg}$ in $(\mathrm{C})$ & & & & & & & & & & & & \\
\hline Av. val. of $\mathrm{Mg}$ in (B) & & & & & Resista & $=1.69$ & Iscepti & $e=1.24$ & & & & \\
\hline Av. val. of $\mathrm{Mg}$ in (A) & & & & & n-Inocu & ted $=0.2$ & Inocu & ted $=0$. & & & & \\
\hline & & & & & $\operatorname{dium}(\mathrm{p}$ & & & & & & & \\
\hline Value of $\mathrm{Na}$ in $(\mathrm{C})$ & 0.76 & 2.05 & 0.42 & 1.85 & 0.52 & 1.96 & 0.24 & 1.45 & 0.35 & 1.65 & 0.24 & 1.55 \\
\hline Av. val. of $\mathrm{Na}$ in (C) & & & & & & & & & & & & \\
\hline Av. val. of $\mathrm{Na}$ in (B) & & & & & Resista & $=1.26$ & Iscepti & $e=0.91$ & & & & \\
\hline Av. val. of $\mathrm{Na}$ in (A) & & & & & n-Inocu & ted $=1$. & Inocu & ted $=0$. & & & & \\
\hline & & & & & inc $(\mathrm{pp}$ & & & & & & & \\
\hline Value of Zinc in (C) & 0.30 & 2.67 & 0.26 & 2.23 & 0.29 & 2.43 & 0.12 & 1.34 & 0.14 & 1.46 & 0.16 & 1.76 \\
\hline Av. val. of Zinc in (C) & & & & & & & & & & & & \\
\hline Av. val. of Zinc in (B) & & & & & Resista & $=1.36$ & Iscepti & $e=0.83$ & & & & \\
\hline Av. val. of Zinc in (A) & & & & & n-Inocu & ted $=1$. & Inocu & ted $=0$. & & & & \\
\hline & & & & & on (ppr & & & & & & & \\
\hline Value of $\mathrm{Fe}$ in $(\mathrm{C})$ & 0.94 & 3.93 & 0.85 & 3.55 & 0.89 & 4.39 & 0.43 & 1.99 & 0.49 & 2.25 & 0.51 & 2.43 \\
\hline Av. val. of $\mathrm{Fe}$ in $(\mathrm{C})$ & & & & & & & & & & & & \\
\hline Av. val. of $\mathrm{Fe}$ in (B) & & & & & Resista & $=2.43$ & Iscepti & $\mathrm{e}=1.35$ & & & & \\
\hline Av. val. of $\mathrm{Fe}$ in $(\mathrm{A})$ & & & & & n-Inocu & ted $=3$ & Inocu & ted $=0$ & & & & \\
\hline & & & & & pper $(\mathrm{p}$ & & & & & & & \\
\hline Value of $\mathrm{Cu}$ in $(\mathrm{C})$ & 1.73 & 4.23 & 1.52 & 3.94 & 1.66 & 4.14 & 1.24 & 2.87 & 1.35 & 2.69 & 1.45 & 2.48 \\
\hline Av. val. of $\mathrm{Cu}$ in $(\mathrm{C})$ & & & & & & & & & & & & \\
\hline Av. val. of $\mathrm{Cu}$ in (B) & & & & & Resista & $=2.87$ & Iscepti & $e=2.22$ & & & & \\
\hline Av. val. of $\mathrm{Cu}$ in (A) & & & & & n-Inocu & ted $=3.3$ & Inocu & ted $=1$. & & & & \\
\hline
\end{tabular}

Percent of total variance of Nitrogen was calculated through statistical analysis and found $6.45 \%$ for groups whereas $92.84 \%$ for types (Table 1). Maximum value of $\mathrm{N}$ concentration was exhibited by the resistant variety Riograndae $(6.92 \%)$ and minimum $(5.01 \%)$ by susceptible variety T-88572 (Table 2).

Difference in phosphorus concentration between 2 groups (inoculated $0.48 \%$ and un-inoculated $1.61 \%$ ) was observed significant in tomato leaves (Table. 2) whereas percent of total variance of Phosphorus was 5.49\% (Table 1). Similarly, average amount of $\mathrm{P}$ in resistant varieties (Riograndae, basket and Roma) is $1.19 \%$ while average amount of phosphorus in susceptible varieties (T-88572, BHN-1021 and BHN-961) is $0.91 \%$. Maximum value of $\mathrm{P}$ concentration was exhibited by resistant variety "Roma" $(1.26 \%)$ and minimum $(0.80 \%)$ by $\mathrm{T}-88572$ susceptible variety (Table 2 ). In case of potassium, significant variation was exhibited by inoculated $(3.38 \mathrm{ppm})$ and un-inoculated plant leaves 10.45ppm (Table 2). The 1318 
percent of total variance (88.61) was exhibited by type (resistant vs susceptible) while $11.10 \%$ by group (inoculated vs un-inoculated) (Table 1). High concentration of potassium was shown by resistant variety i.e., Roma $(8.13 \mathrm{ppm})$ as compared to susceptible tomato variety namely $\mathrm{T}-88572$ exhibited 5.69ppm (Table 2).

Varieties with $1.89 \%$ of total variance, group (resistant vs susceptible) with $3.51 \%$ while type (inoculated vs uninoculated) expressed $92.83 \%$ of the total variance of Calcium (Table 1). Significant variation was exhibited by calcium (inoculated $=1.17 \mathrm{ppm}$ and un-inoculated $=2.50 \mathrm{ppm}$ ). Resistant group expressed 1.973 ppm while susceptible group exhibited 1.693ppm of calcium concentration (Table 2). Maximum amount of $\mathrm{Ca}$ was expressed by resistant variety Riograndae (2.06ppm) while minimum by susceptible variety T-88572 (1.56 ppm). Significant difference in $\mathrm{Mg}$ concentration was indicated by Nested ANOVA types, groups and variety with $92.74,6.45$ and $0.78 \%$ of the total variance (Table 1). Resistant and susceptible type exhibited 1.69 and $1.24 \mathrm{ppm}$ of $\mathrm{Mg}$ while un-inoculated varieties expressed 2.50 ppm as compared to inoculated $(1.17 \mathrm{ppm})$ during disease attack (Table 2).

Inoculated (0.42ppm) and un-inoculated leaves (1.75ppm) of tomato plants exhibited significant variation in concentration of sodium (Table 2) with $92.29 \%$ of the total variance (Table 1) while resistant group expressed 1.26 and susceptible one showed $0.91 \mathrm{ppm}$ of sodium. Maximum amount of $\mathrm{Na}$ was determined in variety Riograndae (1.40ppm) as compared to other varieties (Table 2). Similarly, in case of Zinc concentration, resistant group of tomato leaves expressed $1.36 \mathrm{ppm}$ and susceptible one exhibited $0.83 \mathrm{ppm}$ concentration of $\mathrm{Zn}$ (Table 2) with $12.49 \%$ of the total variance while inoculated type of tomato plants expressed 0.21 and un-inoculated $1.98 \mathrm{ppm}$ of Zinc concentration with $86.06 \%$ of the total variance (Table 1$)$. Minimum amount of Zinc was noted in T-88572 (0.79 ppm) while maximum in Riograndae with 1.48 ppm of Zinc concentration with $1.43 \%$ of the total variance (Table $1 \& 2$ ). Resistant and susceptible group of tomato leaves exhibited significant variation in $\mathrm{Fe}$ contents $(2.43,1.35 \mathrm{ppm}$ respectively) with $22.05 \%$ of the total variance while in case of varieties Riograndae exhibited $2.44 \mathrm{ppm}$ and T-88572 $=0.79 \mathrm{ppm}$ contents of Fe with 0.94 $\%$ of the total variance. Significant variation in contents of $\mathrm{Cu}$ was noted in un-inoculated and inoculated type of tomato leaves i.e., 3.39 and 1.49 ppm with $73.93 \%$ of the total variance. Similar results were noted in group (resistant vs susceptible) and varieties with 25.06 and $0.96 \%$ of the total variance (Table $1 \& 2$ ).

\section{DISCUSSION}

Minerals expressed a pronounced effect on the vigor, physiology, resistance, and biochemical reactions taking place within plants. Pathogens attack on the plants to snatch minerals to perform their activities and excessiveness or reduction in these minerals may increase resistance/ susceptibility of host plant or enhance/ reduce aggressiveness of pathogens. Balanced amount of nutrients in host plant can minimize its fragility towards fungal pathogens and can induce resistance in host plants against different microbes. All physiological, biochemical and metabolic processes were observed more efficient than those host plants which received deficient or excessive quantity of nutrients (Curci et al., 2017). That is why, the current study was designed to evaluate the impact of $A$. solani causing early blight of tomato as well as to observe alterations in minerals contents of resistant and susceptible cultivars. In contemporary studies significant variation in concentrations of $\mathrm{N}, \mathrm{P}, \mathrm{K}, \mathrm{Ca}, \mathrm{Mg}, \mathrm{Fe}, \mathrm{Zn}$ and copper was observed.

Nitrogen is a key component of amino acids, purines and pyrimidine rings of nucleic acids, proteins, enzymes and chlorophyll of the plants (Miller et al. 2007). Its deficiency reduces the ability of plants to uptake other nutrients (Curci et al., 2017). A low concentration of nitrogen in a growth medium favors some diseases in plants. Plants show nitrogen deficiency which are attacked by necrotrophic fungi. Nitrogen expresses statistically different effects depending upon type of the pathogen (Benard et al., 2009). High $\mathrm{N}$ application decreases the severity of the infection against facultative parasites like Alternaria species (Dordas 2008). In present study, Nitrogen (\%) was significantly higher in resistant than susceptible and un-inoculated than inoculated leaves of tomato plants. These results are supported by the work of Veverka et al.,(2007) who reported that $\mathrm{N}$ contents are reduced after the attack of fungal pathogen. Phosphorus plays an important role in the formation of phospholipids, nucleic acids, ADP, ATP, coenzymes (NAD and NADP) and other high energy compounds (Jones et al., 2012). In current study, Phosphorus concentration was observed higher in leaves of resistant and un-inoculated plants than susceptible and inoculated plants. These outcomes are in agreement with the results of Babu et al.,(2015) who reported reduction in amount of $\mathrm{P}$ after attack of ealy blight of tomato. Potassium activates the enzymes involved in carbohydrate metabolism (Akhtar et al., 2010). The reduction of $\mathrm{K}$ concentration in leaves affects the photosynthetic process because it plays a prime role in stomatal opening. In the present study, $\mathrm{K}$ was observed in both susceptible and resistant varieties. There was considerably low concentration in the susceptible plant. Reduction in $\mathrm{K}$ concentration enhances the severity of early blight in susceptible cultivars (El-mougy and Abdel-Kader 2009) because plants deficit in $\mathrm{K}$ are vulnerable to attack of early blight of tomato.

Calcium is an essential element of the plant cell which is absorbed by plants in the form of $\mathrm{Ca}^{+}$(Aghofack-Nguemeziet al., 2014). Calcium foliar treatments are known to enhance resistance against many fungal pathogens by improving the structural integrity of the cell wall. In current study, low

\section{9}


concentration of calcium was observed in inoculated leaves of both resistant and susceptible cultivars. These results are in line with the finding of Dordas, (2008) who observed the low calcium contents in plants affected with fungal pathogens. Magnesium also plays an important role in the overall mechanism of plant growth and is a key constituent of chlorophyll. The $\mathrm{Mg}$ concentration of resistant varieties was significantly higher than susceptible ones which was also witnessed by Aghofack-Nguemezi, (2014) who reported higher contents $\mathrm{Mg}$ in resistant cultivars of tomato which strengthened resistance of tomato plants towards early blight disease. $\mathrm{Na}$ has a role in chlorophyll synthesis and helps in metabolism of plants. In contemporary study, sodium (Na) contents were observed higher in un-inoculated resistant/ susceptible cultivars and lower in inoculated plants. ElMougy\& Abdel-Kader (2009) reported that the application of sodium against Alternaria solani resulted in the fungal growth inhibition in the in-vitro experiments.

Zinc plays a key role among plant's minerals as it is an important component of many enzymes and proteins which triggers the growth and production hormones along with internode elongation. Its deficiency can upset different physiological and biochemical processes in the host plants. In the present study, Zinc contents in resistant tomato cultivars were higher than susceptible tomato varieties. Findings of the present study are supported by the work of Machado et al.,(2018) who reported that $\mathrm{Zn}$ improved the defense system of tomato plants towards early blight infection in potato by providing a positive impact on plant growth and the severity of disease.

Iron plays an important role in chlorophyll production, nucleic acid metabolism, protein synthesis, acts as oxygen carrier and required for $\mathrm{N}$ fixation. Its deficiency causes different maladies in plants. Similarly, $\mathrm{Cu}$ plays an imperative role in photosynthetic process and in respiration process to control electron transport chain. It involves in metabolism of cell wall, provides protection against oxidative stress and also it has strong antifungal and antibacterial properties. So, its deficiency alters different physiological functions of the plants and makes the plants vulnerable to the attack of pathogens (Yuerla., 2009). In current studies, higher concentration of copper and iron was noted in resistant and un-inoculated plants as compared to susceptible and inoculated plants. These findings are supported by the work of Noulas et al.,(2018) who reported higer concentration of copper and iron in resistant plants towards diseases.

Conclusion: All resistant and un-inoculated tomato varieties have higher values of Nitrogen, Phosphorus, Potassium, Calcium, Magnesium, Sodium, Iron, Copper and Zinc than susceptible and inoculated ones. Application of balanced nutrients is the most suitable strategy to manage the early blight disease of tomato.
Acknowledgements: I am highly thankful to Citrus Pathology Laboratory, Department of Plant Pathology, UAF, Pakistan and Centre for Phytophthora Science and Management (CPSM), Murdoch University, Perth, WA, Australia for help in research work and improvement in writing skills as well.

\section{REFRENCES}

Aghofack-Nguemezi J., G.T. Noumbo and C.N. Nkumbe. 2014. Influence of calcium and magnesium based fertilizers on fungal diseases, plant growth parameters and fruit quality of three varieties of tomato (Solanum lycopersicum). J. Sci. Tech. 34: 9-20

Akhtar K., N. Sarwar, M. Saleem and M. Asghar. 2011. Convolvulus arvensis, a new host for Alternaria solani causing early blight of Solanum lycopersicum in Pakistan Australasian plant disease notes. 6:84-86

Akhtar M.E., M.Z. Khan, M.T. Rashid, Z. Ahsan and S. Ahmad. 2010. Effect of potash application on yield and quality of tomato (Lycopersicon esculentum Mill.) Pak. J. Bot. 42:1695-1702

Benard, C., H. Gautier, F. Bourgaud, D. Grasselly, B. Navez, C. Caris-Veyrat and M. Genard. 2009. Effects of low nitrogen supply on tomato (Solanum lycopersicum) fruit yield and quality with special emphasis on sugars, acids, ascorbate, carotenoids, and phenolic compounds. J. Agr. Food. Chem. 57:4112-4123.

Bhargava, B. and H. Raghupathi. 1993. Analysis of plant materials for macro and micronutrients In: Methods of Analysis of Soils, Plants, Waters and Fertilizers: HLS Tandon Fertilizer Development and Consultation Organization.pp.1-2

Bhargava, B. and H. Raghupathi. 1995. Current status and new norms of nitrogen nutrition for grapevine (Vitis vinifera) Indian J. Agric. Sci.

Boltz, D.F. and M.G. Mellon. 1948. Spectrophotometric Determination of Phosphorus as Molybdiphosphoric Acid. Anal Chem. 20:749-751.

Capula-Rodríguez, R., L.A. Valdez-Aguilar, D.L. Cartmill, A.D. Cartmill and I. Alia-Tejacal. 2016. Supplementary calcium and potassium improve the response of tomato (Solanum lycopersicum L.) to simultaneous alkalinity, salinity, and boron stress. Commun. Soil Sci. Plant Ana .47:505-511

Chaerani, R., R. Groenwold, P. Stam and R.E. Voorrips. 2007. Assessment of early blight (Alternaria solani) resistance in tomato using a droplet inoculation method. J. Gen. Plant Pathol. 73:96-103

Curci, P.L., R.A. Cigliano, D.L. Zuluaga, M. Janni, W. Sanseverino and G. Sonnante. 2017. Transcriptomic response of durum wheat to nitrogen starvation. Sci. Rep. $7: 1176$

Datnoff, L., W. Elmer and D.M. Huber. 2007. Mineral nutrition and plant disease. American Phytopathological Society. APS Press, St. Paul. pp.278 
Dordas, C. 2008. Role of nutrients in controlling plant diseases in sustainable agriculture. A review. Agron. Sustain. Dev. 28: 33-46.

el-mougy, N. and M. Abdel-Kader. 2009. Salts Application for Suppressing Potato Early Blight Disease. J. Plant Prot. Res. 49 doi:10.2478/v10045-009-0055-8

Fageria, N. and L. Stone. 2006. Physical, chemical, and biological changes in the rhizosphere and nutrient availability. J. Plant Nutr. 29:1327-1356

Food and Agriculture Organization of United Nation, 2017. FAOSTAT statistics database

Gleason, M. and B. Edmunds. 2006. Tomato diseases and disorders: Iowa State University, University Extension United States.

Gomez, K.A. and A. Gomez. 1984. Statistical procedures for agricultural research. John Willey and Sons Inc New York 641

Grigolli, J.F.J., M.M. Kubota, D.P. Alves, G.B. Rodrigues, C.R. Cardoso, DJ.Hd. Silva and E.S.G. Mizubuti. 2011. Characterization of tomato accessions for resistance to early blight. Crop. Breed. Appl. Biot. 11:174-180

Helrich, K. 1990. Official Methods of Analysis, Volume 2: Food Composition; Additives; Natural Contaminants, Arlington, VA: Association of Official Analytical Chemists. Inc.

Huber, D.M. and J.B. Jones. 2013. The role of magnesium in plant disease. Plant and Soil. 368: 73-85.

Institute, S. 2009. Using JMP Student Edition for Windows and Macintosh: The User's Guide to Statistics with JMP Student Edition. SAS Institute,

Jones, D., J. Rousk, G. Edwards-Jones, T. DeLuca and D. Murphy. 2012. Biochar-mediated changes in soil quality and plant growth in a three year field trial. Soil Biol. 45:113-124

Jung, S., D. Rickert, N. Deak, E. Aldin, J. Recknor, L. Johnson and P. Murphy. 2003. Comparison of Kjeldahl and Dumas methods for determining protein contents of soybean products. J. Am. Oil Chem.' Soc. 80:1169

Khan, A. L., M. Waqas, S. M. Kang, A. Al-Harrasi, J. Hussain, A. Al-Rawahi and I.J. Lee. 2014. Bacterial endophyte Sphingomonas sp. LK11 produces gibberellins and IAA and promotes tomato plant growth. J. Micro. 52:689-695.

Machado, P.P., F. Steiner, A.M. Zuffo and R.A. Machado. 2018. Could the Supply of Boron and Zinc Improve Resistance of Potato to Early Blight Potato Research. 61:169-182

Malvi, U.R. 2011. Interaction of micronutrients with major nutrients with special reference to potassium Karnataka. J. Agr. Sci. 24:106-109.
Mari, F.M. and H.D. Lohano. 2007. Measuring Production Function and Technical Efficiency of Onion, Tomato, and Chillies Farms in Sindh, Pakistan. The Pakistan Development Review.46:1053-1064

Mengel, K. 2001. Alternative or complementary role of foliar supply in mineral nutrition. In: International Symposium on Foliar Nutrition of Perennial Fruit Plants. 594:33-47

Mengel, K., E.A. Kirkby, H. Kosegarten and T. Appel. 2001. Plant nutrients. In: Principles of plant nutrition. Springer. pp.1-13

Miller, A.J., X. Fan, Q. Shen and S.J. Smith. 2007. Amino acids and nitrate as signals for the regulation of nitrogen acquisition. J. Exp. Bot. 59:111-119

Misra, A., A.K. Srivastava, N.K. Srivastava and A. Khan. 2005. Zn-acquisition and its role in growth, photosynthesis, photosynthetic pigments, and biochemical changes in essential monoterpene oil (s) of Pelargonium graveolens. Photosynthetica. 43:153-155.

Mitra, G.N. 2015. Regulation of nutrient uptake by plants New Delhi: Springer. DOI 10:978-981

Momel, T. and K. Pemezny. 2006. Florida plant disease management guide: tomato, Florida Cooperative Extension Service. Institute of Food and Agricultural Sciences. PDMG-V3-53. En: http://edis. ifas. ufl. edu/PG059,

Naik, M., Y. Prasad, K. Bhat and G.D. Rani. 2010. Morphological, physiological, pathogenic and molecular variability among isolates of Alternaria solani from tomato. Ind. Phytopathol. 63:168-173

Narendra Babu, A., S. Jogaiah, S-i. Ito, A. Kestur-Nagaraj and L-S.P. Tran. 2015. Improvement of growth, fruit weight and early blight disease protection of tomato plants by rhizosphere bacteria is correlated with their beneficial traits and induced biosynthesis of antioxidant peroxidase and polyphenol oxidase Plant Science. 231:62-73.

Noulas, C., M. Tziouvalekas and T. Karyotis. 2018. Zinc in soils, water and food crops. J. Trace. Elem. Med. Bio. 49:252-260

Olaniyi, J., W. Akanbi, T. Adejumo and O. Ak. 2010. Growth, fruit yield and nutritional quality of tomato varieties. Afr. J. Food Sci. 4:398-402

Sgherri, C., Z. Kadlecová, A. Pardossi, F. Navari-Izzo and R. Izzo. 2008. Irrigation with Diluted Seawater Improves the Nutritional Value of Cherry Tomatoes. J. Agr. Food Chem. 56: 3391-3397.

Veverka, K., J. Štolcová and P. Růžek. 2007. Sensitivity of fungi to urea, ammonium nitrate and their quimolar solution. UAN Plant Prot. Sci. 43:157-164.

Yruela, I. 2009. Copper in plants: acquisition, transport and interactions. Funct. Plant. Biol.36: 409-430. 